\title{
Pioglitazone and risk of bladder cancer: clarification of the design of the French study. Reply to Perez AT [letter]
}

\author{
A. Neumann • A. Weill • P. Ricordeau • J. P. Fagot \\ F. Alla $\cdot$ H. Allemand
}

Received: 21 September 2012 / Accepted: 3 October 2012 /Published online: 11 November 2012

(C) Springer-Verlag Berlin Heidelberg 2012

Keywords Adverse effects $\cdot$ Bladder cancer $\cdot$ Cohort · France $\cdot$ Pharmacoepidemiology $\cdot$ Pioglitazone $\cdot$

Reimbursement database

To the Editor: In his letter, Dr Perez [1] questioned the rationale for our choice to present the results in patients aged 40 to 79 years in our study [2], while analyses that extended to all patients aged $\geq 40$ years were possible and had been initially envisaged. Our decision was based on limitations of the available data as revealed by external data validation. In France, a national cancer registry covering the whole country is not available. In our study, cases of bladder cancer were therefore identified through a database linking hospital data and reimbursement data. We defined cases of bladder cancer based on a diagnosis code for bladder cancer (ICD-10 code C67; www.who.int/classifications/icd/en/) in the hospital database and a specific surgical procedure (total cystectomy by laparotomy, or partial cystectomy by laparotomy or laparoscopy) and/or intravesical instillation of a pharmacological product by urethral catheter and/or chemotherapy and/or radiation therapy performed during the same hospital stay. The incidence rates of bladder cancer resulting from this algorithm in patients aged 40 to 79 years were very similar to those reported by the French cancer registries (réseau des registres français de cancer [Francim] [3]), which cover various geographical sectors (Fig. 1). However, after the age of 80 years, the incidence curves diverge

\footnotetext{
A. Neumann $\cdot$ A. Weill $(\bowtie) \cdot$ P. Ricordeau $\cdot$ J. P. Fagot $\cdot$ F. Alla $\cdot$

H. Allemand

Caisse Nationale de l'Assurance Maladie,

50 Avenue du Pr André Lemierre,

75986 Paris Cedex 20, France

e-mail: alain.weill@cnamts.fr
}

considerably, probably because not all bladder cancers are treated intensively at this age. The misclassification of bladder cancer cases in this age group is such that it did not appear feasible to draw any valid conclusions, which is why we decided to limit our analysis to results obtained in patients aged 40 to 79 years.

Perez also regretted the absence of certain covariates (history of diabetes, smoking, etc.) in our database. However, partial data were available and provided strong arguments in favour of the validity of our results despite the absence of these covariables in the main model. In particular, the duration of diabetes was estimated by the date at which patients were declared as being diabetic to the French national health insurance system, in order to obtain better financial coverage for their care. This result is presented in our article [2] as is the result in relation to smoking that suggests a possible underestimation of the risk of bladder cancer related to exposure to pioglitazone.

It is nevertheless true that all studies contain certain limitations, which is why it is essential to interpret the study results by taking into account possible biases, but also in the light of the results of other studies conducted by other teams on the same subject. In this particular case, since the publication of our article in Diabetologia, other studies have been published. Azoulay et al [4] showed that more than 2 years of daily exposure to pioglitazone doubled the risk of bladder cancer (adjusted HR 1.83 [95\% CI 1.10, 3.05]). A metaanalysis by Colmers et al [5] also reported the existence of a significant association (adjusted HR 1.15 [95\% CI 1.05, 1.24]). These various elements appear to confirm the validity of the results presented in our study, indicating a significant increase in the risk of bladder cancer in patients exposed to pioglitazone (adjusted HR 1.22 [95\% CI 1.05, 1.43]), with a marked dose-effect relationship, a relationship also demonstrated by Mamtani et al [6]. 
a

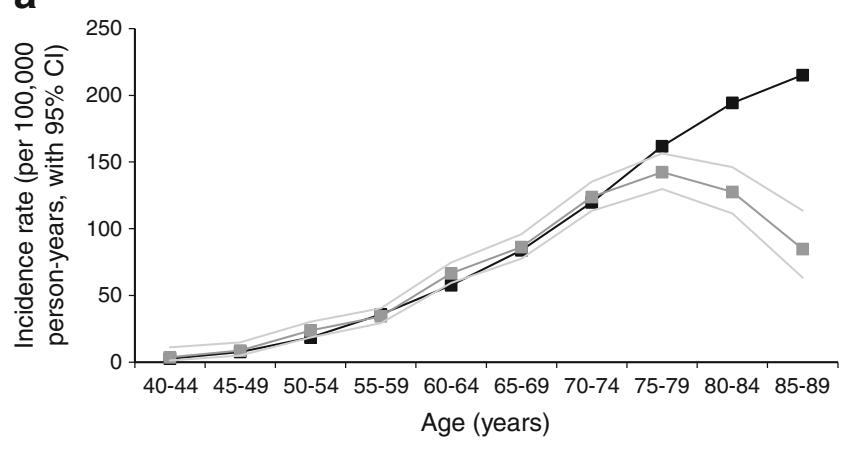

b

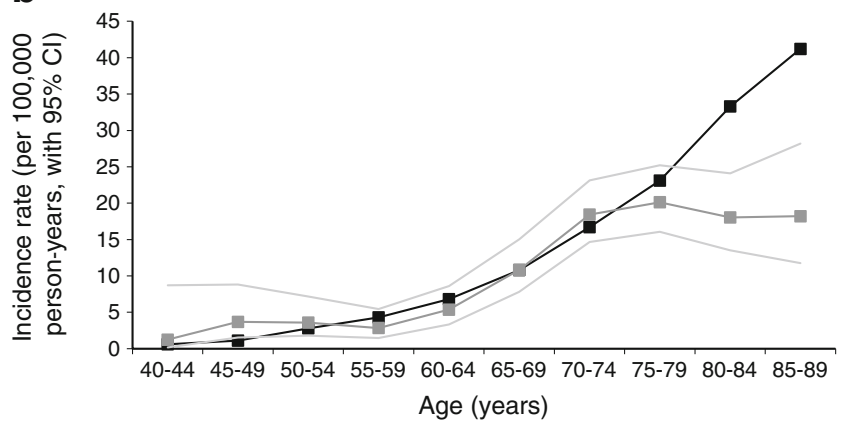

Fig. 1 Incidence rates of bladder cancer by sex for men (a) and women (b) and age: black squares, French cancer registry data [3]; grey squares, pioglitazone study criteria [2]. Reproduced from our original report to the French medicines agency (ANSM) [7]

Duality of interest No private company sponsored this project. All authors are employees of public institutions. The authors declare that there is no duality of interest associated with this manuscript.
Contribution statement All authors contributed to drafting or critical revision of the letter; they gave their final approval of the version to be published.

\section{References}

1. Perez AT (2012) Pioglitazone and risk of bladder cancer: clarification of the design of the French study. Diabetologia. doi:10.1007/ s00125-012-2767-y

2. Neumann A, Weill A, Ricordeau P, Fagot JP, Alla F, Allemand H (2012) Pioglitazone and risk of bladder cancer among diabetic patients in France: a population-based cohort study. Diabetologia 55:1953-1962

3. Bélot A, Velten M, Grosclaude P et al (2008) [National estimate of the incidence and mortality from cancer in France between 1980 and 2005]. Saint-Maurice (Fra), Institut de veille sanitaire. Available from www.invs.sante.fr/publications/2009/estimation_cancer 1980 2005/estimation cancer 1980 2005.pdf, accessed $1 \overline{0}$ September 2012 [article in French]

4. Azoulay L, Yin H, Filion KB et al (2012) The use of pioglitazone and the risk of bladder cancer in people with type 2 diabetes: nested case-control study. BMJ 344:e3645

5. Colmers IN, Bowker SL, Majumdar SR, Johnson JA (2012) Use of thiazolidinediones and the risk of bladder cancer among people with type 2 diabetes: a meta-analysis. CMAJ 184:E675E683

6. Mamtani R, Haynes K, Bilker WB et al (2012) Association between longer therapy with thiazolidinediones and risk of bladder cancer: a cohort study. J Natl Cancer Inst 104:1411-1421

7. Caisse nationale de l'assurance maladie (2011) Risque de cancer de la vessie chez les personnes diabétiques traitées par pioglitazone en France: une étude de cohorte sur les donnée du SNIIRAM et du PMSI. Available at http://ansm.sante.fr/content/download/34024/ 445581/version/1/file/RapportEtudeCNAMTS-Pioglitazone-juin20113.pdf, accessed 9 June 2011 [article in French] 